\title{
A novel quantification method for the total demethylation potential of aquatic sample extracts from Bohai Bay using the EGFP reporter gene
}

\author{
Yan Qian ${ }^{1 \dagger}$, Xiaoli Wang ${ }^{2+}$, Zhanlu Lv', Chen Guo ${ }^{1}$, Mei Han ${ }^{1}$, Jiabing $\mathrm{Wu}^{1,3}$, Yongjian Yang ${ }^{3}$, Yishu Yang ${ }^{2}$, \\ Yan Jiang ${ }^{1}$, Yongjie Wei ${ }^{1}$, Jing Nie ${ }^{1}$, Bao Liang ${ }^{1,3}$, Jinliang Zhang ${ }^{1}$ and Xianliang Wang ${ }^{1,4^{*}}$
}

\begin{abstract}
Background: The demethylation potential of environmental pollutants is possibly an innate part of their comprehensive health risk. This paper develops a novel method called TDQ to quantify the demethylation epigenetic toxicity, termed the 5-AZA-CdR demethylation toxic equivalency, of aquatic samples from the heavily polluted Bohai Bay using Hep G2 cell lines transiently transfected with the pEGFP-C3 plasmid containing a methylated promoter of the EGFP reporter gene inserted artificially in vitro.

Results: If the aquatic sample extract has strong total demethylation potential to the promoter, its methylation level will decrease, and increased green fluorescence will be observed under microscopy after TDQ co-incubation. The 5-AZA-CdR was selected as a representative demethylation agent to validate the principle of the TDQ method on three levels: significant dose-response relationships between the concentration of 5-AZA-CdR and the methylation level of promoters, mRNA expression level of the EGFP gene, and the fluorescence intensity of EGFP proteins. Twenty extracts from aquatic samples are successfully quantified with the TDQ test. Eight of them return meaningful results ranging from 0.00004 to $0.20053 \mu \mathrm{M}$ 5-AZA-CdR toxicity equivalents.
\end{abstract}

Conclusions: The TDQ method is a reliable and rapid assay for the quantification of the DNA demethylation potential of aquatic sample extracts, which may shed light on the safety evaluation of food material.

Keywords: Demethylation, Aquatic sample, EGFP, Metals, Bohai bay

\section{Background}

Health risks from environmental pollution in China have become increasingly important to public concern, especially in terms of food safety. Many toxicological methods have been invented to test for the presence of gene mutations and chromosome aberrations due to environmental pollutants, such as the Salmonella reverse mutation assay for mutagenic activities and the comet assay for chromosome damage [1]. Some research has

\footnotetext{
* Correspondence: XIwang@craes.org.cn

${ }^{\dagger}$ Equal contributors

'State Key Laboratory of Environmental Criteria and Risk Assessment, Chinese Research Academy of Environmental Sciences, Beijing 100012, China ${ }^{4}$ Institute of Environmental Health and Related Product Safety, Chinese Center for Disease Control and Prevention, Beijing 100021, China
} Full list of author information is available at the end of the article shown that epigenetic negative effect of environmental pollutants in food materials cannot be overlooked. The epigenetic mechanism has become one of the focusing fields for the etiology of many disorders, including the adverse effect of many environmental pollutants, such as heavy metals, during the last decade. The primary function of DNA methylation for regulatory elements is to down-modulate gene expression. Epigenetic changes, including global DNA hypomethylation and hypermethylation of tumor suppressor genes, are frequently observed in cancer cells. DNA methylation is susceptible to change and an excellent candidate for explaining how certain environmental factors may increase the risk of cancer [2, 3].

Cadmium increases DNA methylation and the expression of DNMT1 and DNMT3a mRNA in the 
livers and kidneys of hens, implying that DNA methylation may be involved in the carcinogenic action of cadmium [4]. Environmental cadmium exposure was associated with DNA hypomethylation in peripheral blood in Argentinean women [5]. The genetic reactivation of long interspersed nuclear element-1 by benzo(a)pyrene involves reduced DNA methylation of CpG islands [6]. Many pollutants appear to have the potential to change the DNA methylation status of key genetic elements, which may be involved in the disorder progression from environmental pollutants in many types of food material.

According to the 2013 China Marine Environmental Quality Communique [7], the costal line water in Bohai Bay abutting the Tianjin metropolitan area has been ranked worst for pollution for many years. Even the living marine mollusks in the coastal sea area abutting the pollution sources are marked by serious heavy metal contamination $[8,9]$. The total toxic demethylation potential of aquatic samples should be examined to evaluate their safety for local residents. Thus far, few studies have reported on assessment methods of DNA methylation alternation for food material. One study reports on the establishment of a detection system for demethylating agents using an endogenous promoter $\mathrm{CpG}$ island [10], but the HCT 116 cell line is a poor candidate tool due to its relative absence of the cytochromes P450 enzymes and corresponding activation of pollutants. Another two-component reporter gene system has been described based on the visualization and quantization of dynamic changes in targeted DNA methylation in bone marrow-derived stem cells or cancer cell lines [11].
The assessment of DNA methylation status is proposed for safety assessment, and the evaluation of the overall methylation status is desirable [12-15]. In the present study, which aims to develop a demethylation toxicity assessment of aquatic samples that can quickly identify potential health risks through epigenetic mechanisms, we report a novel method for the total demethylation potential quantification (TDQ) with the EGFP reporter gene and the artificially methylated promoter in Hep G2 cell lines (Fig. 1).

\section{Results}

Validity of TDQ test for demethylation potential

The 5-aza-2'-deoxycytidine (5-AZA-CdR) was selected as a representative positive demethylation agent to validate the principle of the TDQ method (Fig. 1) on three levels: dose-response relationship exploration between the concentration of 5-AZA-CdR and the methylation level of CMV promoters, mRNA expression level of EGFP gene, and the intensity of cellular fluorescence intensity (Table 1). The Hep G2 cells with successful transfection of pEGFP-C3 plasmids containing methylated promoters grew well after the cell incubation conditions were optimized.

\section{Methylation level of CMV promoter and the treatment of 5-AZA-CdR}

The bisulfite treatment of DNA converts all unmethylated cytosines to uracils, whereas methylated cytosine is unchanged under the reaction condition; thus, methylation status can be determined from different sequences [16]. The decreasing methylation levels of

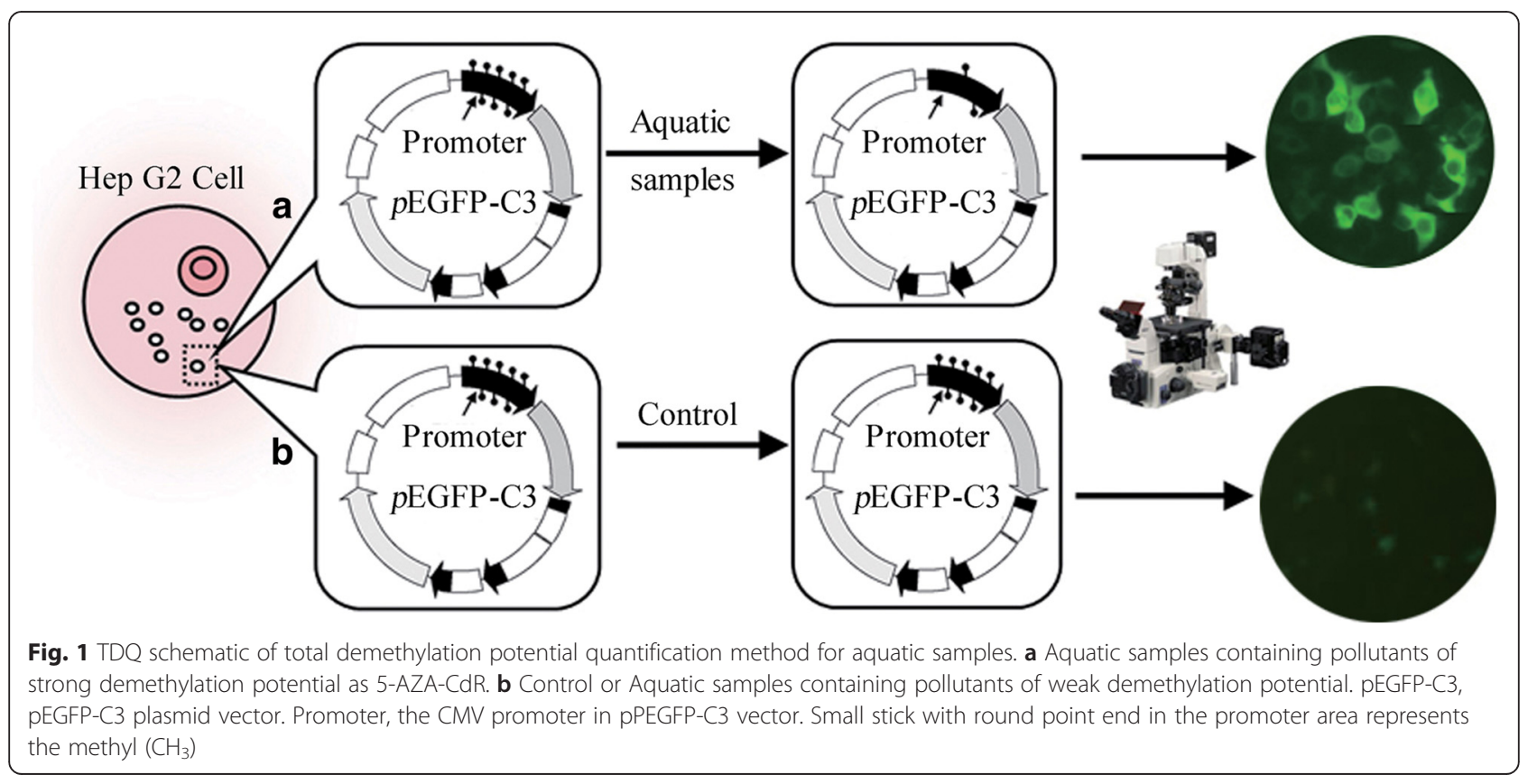


Table 1 The effect of 5-AZA-CdR on the EGFP reporter gene in cells with the TDQ experiment

\begin{tabular}{llcccc}
\hline Groups & $\mathrm{n}$ & 5-AZA-CdR $(\mu \mathrm{M})$ & Methylation level (\%) & EGFP mRNA level & EGFP fluorescence (\%) \\
\hline A0 & 5 & 0.00000 & $91.6 \pm 3.5$ & $1.00 \pm 0.00$ & $2.20 \pm 0.47$ \\
A1 & 5 & 0.00016 & $87.8 \pm 2.1$ & $1.65 \pm 0.34$ & $7.68 \pm 0.87$ \\
A2 & 5 & 0.00080 & $85.5 \pm 2.5$ & $1.77 \pm 0.26$ & $8.75 \pm 1.06$ \\
A3 & 5 & 0.00400 & $79.8 \pm 3.6$ & $1.92 \pm 0.35$ & $9.81 \pm 1.29$ \\
A4 & 5 & 0.02000 & $74.5 \pm 3.2$ & $12.30 \pm 0.93$ & $11.18 \pm 1.39$ \\
\hline
\end{tabular}

Note. Cell groups A0 A4 are treated with different concentrations of 5-AZA-CdR. Methylation levels are the concrete methylation levels of the CMV promoter within Hep G2 cell groups with BSP analysis. EGFP mRNA level are the concrete relative level of EGFP mRNA within Hep G2 cell groups with real-time PCR analysis. EGFP fluorescence is the concrete intensity of fluorescence of Hep G2 cell groups with cytometry analysis. There are significant differences for ANOVA analysis of the methylation level between all groups barring groups $A 0$ and $A 1$ and groups $A 1$ and $A 2$. There are significant differences for ANOVA analysis of the EGFP mRNA level between all groups barring groups $A 1$ and $A 2$, groups $A 2$ and $A 3$, and groups $A 1$ and $A 3$. There are significant differences for ANOVA analysis of the EGFP fluorescence between all groups barring groups $A 1$ and $A 2$, groups $A 2$ and $A 3$, and groups $A 3$ and $A 4$

the CMV promoter were observed from cells treated with increasing 5-AZA-CdR doses with BSP results. The representative BSP results are shown in Fig. 2. There is a significant dose-effect relationship expressed as $y=-2.83 \ln (x)+63.97\left(R^{2}=0.972\right)$ between the 5AZA-CdR treatment and the methylation level of the CMV promoter from corresponding cells in the TDQ test (Fig. 3a), which indicates that CMV promoter methylation is a valid candidate test target for potential demethylation agents.

\section{Expression level of the EGFP gene and the treatment of 5-AZA-CdR}

To explore the response of the EGFP gene expression to the treatment of 5-AZA-CdR gradients in the TDQ experiment, the relative mRNA volume of the EGFP gene within the C3 plasmid was evaluated based on a reference GAPDH gene. Increasing expression levels of the target gene from different cell wells were found with increasing concentrations of 5-AZA-CdR (Additional file 1: Table S1). A significant dose-effect relationship

$$
\begin{aligned}
& \text { a } \\
& \text { GACGGCGACG TA A ACG T T A TA A T T TAGCGTGTTCG GCGA }
\end{aligned}
$$
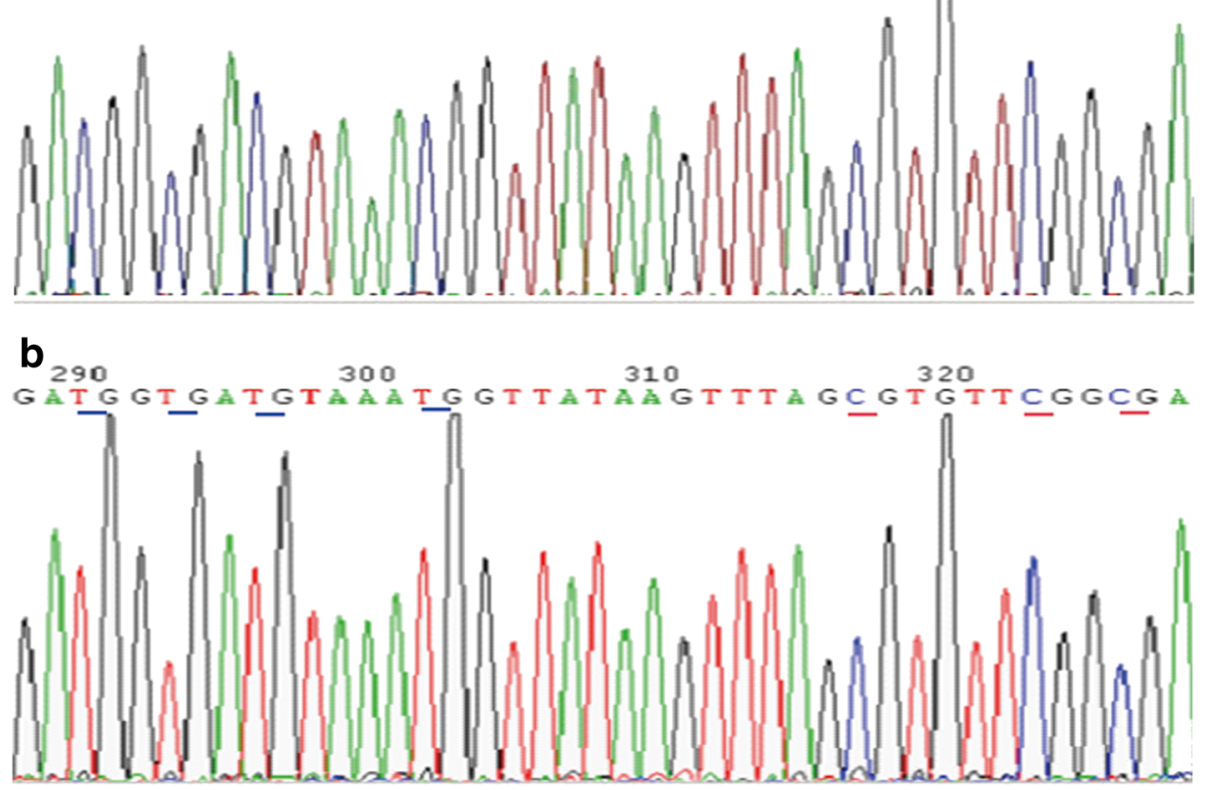

Fig. 2 The representative sequence maps for BSP methylation quantification of the CMV promoter in cells. This map is for the 290-330 bp of the PCR T clones for sequencing. The upper map (a) for the control group: $7 \mathrm{mCGs}$ (blue peaks) did not change after bisulfite treatment and sequencing. The lower map (b) for 5-AZA-CdR group: 4 mCGs changed to TGs (red peaks to the left) due to the methyl lost and 3 mCGs did not change (blue peaks to the right) after bisulfite treatment and sequencing 


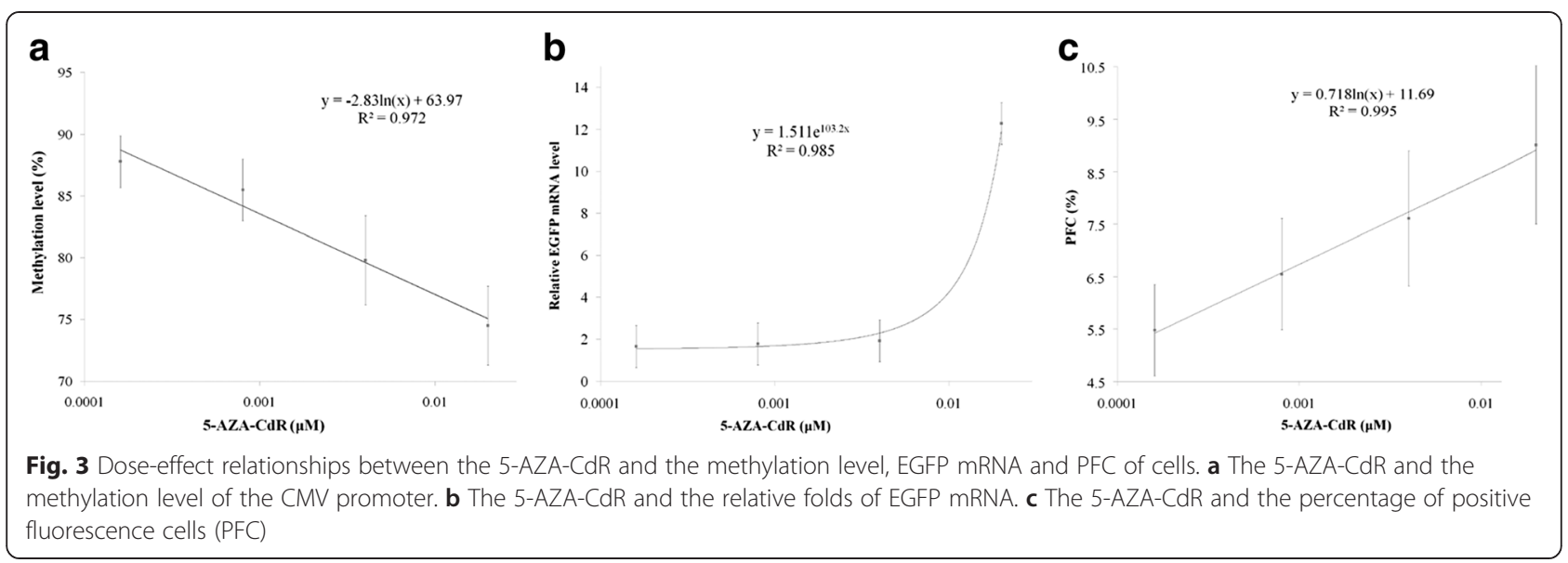

between the 5-AZA-CdR treatment and the relative folds of EGFP mRNA was confirmed with an equation of $y=1.511 \exp (103.2 x) \quad\left(R^{2}=0.985\right) \quad($ Fig. 3b), which indicated that the expression of EGFP mRNA within the C3 plasmid in the Hep G2 cell lines is sensitive to the treatment of 5-AZA-CdR.

\section{Fluorescence intensity of EGFP and treatment of}

\section{5-AZA-CdR}

To explore the response of cells' EGFP fluorescence intensity to the treatment of 5-AZA-CdR gradients in the TDQ experiment, the spontaneous fluorescence intensity of cells with increasing concentrations of 5-AZA-CdR (Table 1) was evaluated directly via microscopy imaging, and later by using flow cytometry measurement to find the percentage of positive fluorescent cells. The cells treated with higher concentration of 5-AZA-CdR have significantly brighter images than those treated with correspondingly lower concentrations (Fig. 4). A significant dose-effect relationship between the 5-AZA-CdR treatment and percentage of positive fluorescent cells was confirmed and expressed by $\mathrm{y}=0.718 \ln (\mathrm{x})+11.69$ $\left(R^{2}=0.995\right)$ (Fig. 3c), which indicated that the spontaneous fluorescence of the EGFP protein from the gene located in the pEGFP-C3 plasmid in the Hep G2 cell lines was sensitive to the treatment of 5-AZA-CdR and possibly to other agents with demethylation potential.

Detection limit of the TDQ test for 5-AZA-CdR experiment To explore the detection limit of the TDQ assay, five samples with relatively lower concentrations of 5-AZACdR (0.0000025, 0.00001, 0.00004, 0.00016, 0.00064 $\mu \mathrm{M})$ were prepared for TDQ test (Additional file 2: Table S2). Results showed that the detectable noise signals varied

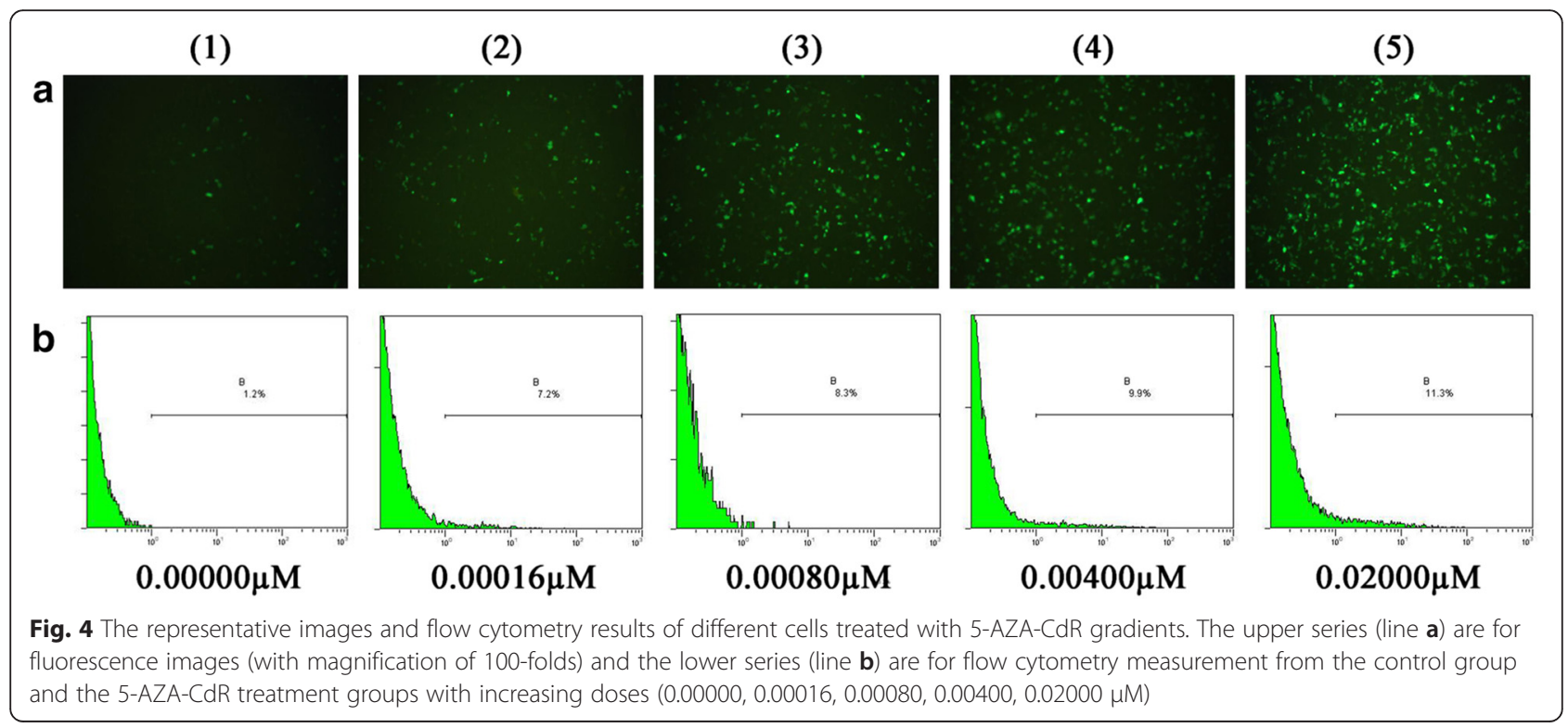


Table 2 Repeated TDQ experiment with cells treated with different doses of 5-AZA-CdR

\begin{tabular}{|c|c|c|c|c|c|c|}
\hline Groups & Original 5-AZA-CdR $(\mu M)$ & $n$ & PFC (\%) & RSD (\%) & Calculated 5-AZA-CdR $(\mu \mathrm{M})$ & RR (\%) \\
\hline$\overline{\mathrm{A} O}$ & 0.00000 & 5 & $2.20 \pm 0.46$ & 21.1 & - & - \\
\hline $\mathrm{A} 1$ & 0.00016 & 5 & $7.48 \pm 0.81$ & 10.8 & 0.000127 & 79.5 \\
\hline$A 2$ & 0.00080 & 5 & $8.72 \pm 1.09$ & 12.5 & 0.000933 & 116.7 \\
\hline A3 & 0.00400 & 5 & $9.66 \pm 1.51$ & 15.7 & 0.003655 & 91.4 \\
\hline A4 & 0.02000 & 5 & $11.18 \pm 1.47$ & 13.1 & 0.025493 & 127.5 \\
\hline
\end{tabular}

Note. PFC is the percentage of positive fluorescence cells of the total cells. RSD is the relative standard deviation. RR is the Recovery Rate of the 5-AZA-CdR calculated for the original 5-AZA-CdR. There are significant differences for ANOVA analysis of PFC between all groups barring groups A1 and A2 and groups A2 and A3

from $0.0000025 \mu \mathrm{M}$ to $0.00001 \mu \mathrm{M}$, and meaningful fluorescence intensity of cells was observed with a concentration higher than $0.00004 \mu \mathrm{M} 5$-AZA-CdR. No significant difference in fluorescence intensity was found between the cell groups treated with 5-AZA-CdR $(0.0000025$ and $0.00001 \mu \mathrm{M})$ and the control cell group, while a significant difference in fluorescence intensity was observed between the cell groups treated with 5AZA-CdR (0.00004, 0.00016 and $0.00064 \mu \mathrm{M})$ and the other cell groups $(0,0.0000025$ and $0.00001 \mu \mathrm{M})$. Therefore, we recognized that the detection limit of TDQ is approximately $0.00004 \mu \mathrm{M} 5$-AZA-CdR.

\section{Accuracy and precision of the TDQ test for 5-AZA-CdR experiment}

To detect the accuracy and precision of the TDQ assay, five samples with moderate concentrations of 5-AZACdR $(0.0000,0.00016,0.0008,0.004,0.02 \mu \mathrm{M})$ were applied simultaneously to perform the demethylation quantification five times (Table 2, Fig. 5). Results showed that the deviation results from the repetitive analysis of the four samples $(0.00016 \sim 0.02 \mu \mathrm{M})$ varied from $11.0 \%$ to $15.7 \%$. The recovery rate for TDQ test varied from $79.5 \%$ to $127.5 \%$. The standard line applied here is $y=\exp \left(-0.071 x^{2}+2.445 x-19.90\right)\left(R^{2}=0.999\right)$.

\section{Optimal check time for TDQ test}

The optimal check time for TDQ test is the suitable time for the user to collect cells for quantification of fluorescence intensity with flow cytometry. The fluorescence intensity of the cells may change at different time of the TDQ timeline. To explore the optimal check time, we took a series of microscope images every $6 \mathrm{~h}$ when the 5-AZA-CdR samples were pipetted into the cell culture medium. Images with meaningful fluorescence were found beginning at Hour 36, and ascended to the peak plat period with the brightest fluorescence between Hour 54 and Hour 72. Additional TDQ test of 5-AZACdR treatment with different dosages $(0.00016,0.00080$ and $0.00400 \mu \mathrm{M}$ ) was conducted (Additional file 3: Table S3). Therefore, Hour 60 was selected as the optimal check time for the entire TDQ test duration.

\section{Quantification of demethylation potential by TDQ in aquatic samples}

To explore the applicability of TDQ method for the quantification of the demethylation of actual aquatic samples, 20 aquatic samples from China's Bohai Bay were collected to prepare the inorganic extracts for further experimentation. Positive demethylation potentials ranging from 0.00004 to $0.20053 \mu \mathrm{M}$ 5-AZA-CdR toxicity equivalents can be observed in eight samples. A sample (MS06) extract from Beitangkou showed the highest demethylation toxic equivalency (DTE) at $0.20053 \mu \mathrm{M} 5$-AZA toxicity equivalent (Table 3). Cd and As were found at $34.73 \mathrm{mg} / \mathrm{Kg}$ and $1.12 \mathrm{mg} / \mathrm{Kg}$ in this sample extract with the later ICP-Mass analysis; both concentrations are higher than the maximum allowable levels for $\mathrm{Cd}$ and As in aquatic food materials in China. All of the samples with observable demethylation potential included the Silurus asotus Linnaeus, Sinonovacula constricta, Bullacta exarata, Venerupis variegata, Scapharca subcrenata, and Rapana venosa.

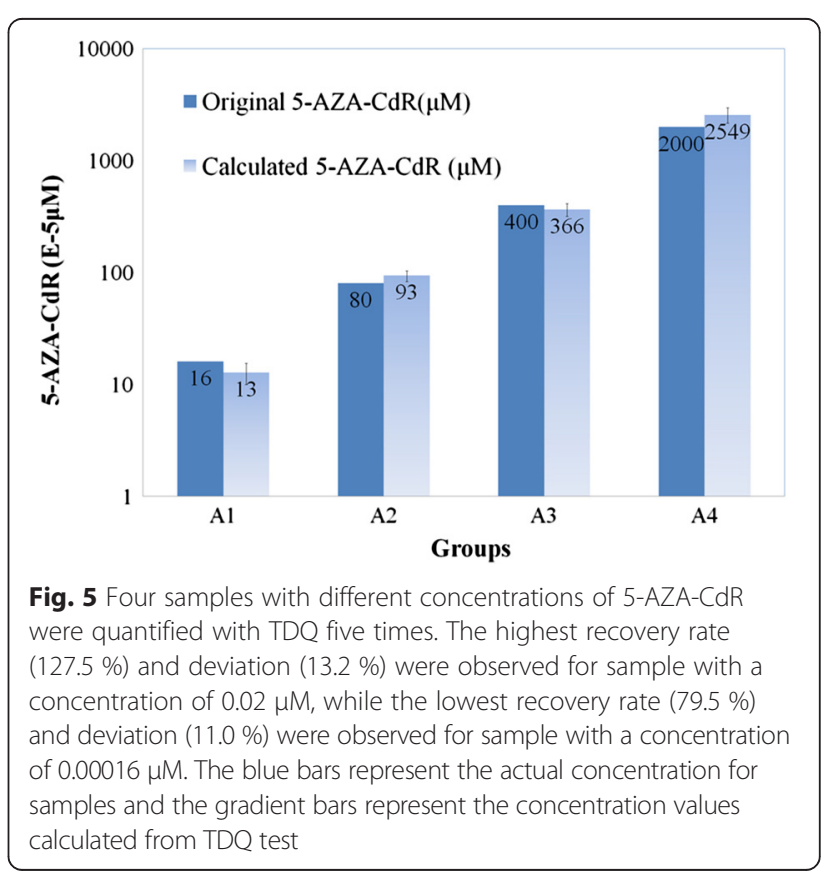


Table 3 The demethylation potential and the pollutants of inorganic extracts of aquatic samples from Bohai bay

\begin{tabular}{|c|c|c|c|c|c|c|c|c|c|c|c|}
\hline Samples & Sites & Name & PFC (\%) & 5-AZA-CdR DTE $(\mu \mathrm{M})$ & $\mathrm{Cd}$ & As & $\mathrm{Cr}$ & $\mathrm{Mn}$ & $\mathrm{Ni}$ & $\mathrm{Pb}$ & $\mathrm{Hg}$ \\
\hline MS01 & A & Rapana venosa & 6.26 & 0.00000 & 0.49 & 2.57 & 0.65 & 10.70 & 0.46 & 0.52 & 0.21 \\
\hline MSO2 & A & Argopectens irradias & 2.41 & 0.00000 & 0.12 & 0.32 & 0.63 & 2.99 & 0.21 & 0.43 & 0.13 \\
\hline MSO3 & A & Silurus asotus Linnaeus & 2.45 & 0.00000 & 0.59 & 0.98 & 0.46 & 13.10 & 0.38 & 0.16 & 0.09 \\
\hline MSO4 & A & Sinonovacula constricta & 0.78 & 0.00000 & 0.38 & 0.31 & 0.97 & 3.78 & 0.53 & 0.28 & 0.10 \\
\hline MS05 & B & Sinonovacula constricta & 12.52 & 0.09611 & 7.38 & 0.35 & 0.35 & 14.28 & 1.36 & 0.90 & 0.02 \\
\hline MS06 & $B$ & Silurus asotus Linnaeus & 13.30 & 0.20053 & 34.73 & 1.12 & 0.42 & 13.21 & 0.34 & 0.18 & 0.07 \\
\hline MS07 & $\mathrm{B}$ & Scapharca subcrenata & 8.60 & 0.00066 & 4.66 & 0.26 & 0.22 & 18.00 & 0.81 & 0.15 & 0.01 \\
\hline MS08 & B & Venerupis variegata & 2.37 & 0.00000 & 0.51 & 1.43 & 2.17 & 6.22 & 2.13 & 0.21 & 0.02 \\
\hline MS09 & C & Bullacta exarata & 4.93 & 0.00000 & 0.85 & 1.99 & 0.43 & 3.84 & 0.49 & 0.11 & 0.08 \\
\hline MS10 & C & Sinonovacula constricta & 2.41 & 0.00000 & 0.27 & 0.24 & 0.24 & 13.87 & 1.27 & 0.86 & 0.00 \\
\hline MS11 & C & Venerupis variegata & 2.38 & 0.00000 & 0.46 & 1.36 & 1.98 & 5.96 & 2.01 & 0.13 & 0.01 \\
\hline MS12 & C & Venerupis variegata & 10.17 & 0.00628 & 5.35 & 1.68 & 2.42 & 6.68 & 2.39 & 0.25 & 0.02 \\
\hline MS13 & D & Venerupis variegata & 3.95 & 0.00000 & 4.99 & 1.49 & 2.33 & 6.53 & 2.25 & 0.24 & 0.03 \\
\hline MS14 & $\mathrm{D}$ & Sinonovacula constricta & 7.01 & 0.00005 & 2.31 & 0.28 & 0.28 & 14.03 & 1.32 & 0.96 & 0.00 \\
\hline MS15 & $\mathrm{D}$ & Rapana venosa & 6.95 & 0.00004 & 0.58 & 0.94 & 0.67 & 16.10 & 0.55 & 0.19 & 0.04 \\
\hline MS16 & $\mathrm{D}$ & Venerupis variegata & 3.13 & 0.00000 & 7.11 & 0.68 & 0.94 & 32.74 & 0.63 & 0.41 & 0.05 \\
\hline MS17 & $E$ & Venerupis variegata & 3.91 & 0.00000 & 0.45 & 1.33 & 2.23 & 6.12 & 2.11 & 0.17 & 0.03 \\
\hline MS18 & $E$ & Scapharca subcrenata & 7.04 & 0.00005 & 5.04 & 0.23 & 0.41 & 8.01 & 0.89 & 0.29 & 0.03 \\
\hline MS19 & $E$ & Bullacta exarata & 10.95 & 0.01701 & 6.85 & 0.33 & 0.71 & 12.05 & 0.32 & 0.46 & 0.05 \\
\hline MS20 & $E$ & Oratosquillina interrupta & 2.35 & 0.00000 & 0.63 & 0.37 & 0.45 & 4.67 & 1.63 & 0.21 & 0.06 \\
\hline $\mathrm{FSV}(\mathrm{mg} / \mathrm{Kg})$ & & & & & 2.0 & 0.5 & 2.0 & - & - & 1.0 & 0.5 \\
\hline
\end{tabular}

Note. Sampling Sites: A, Caijiabao; B, Beitangkou; C, Gaoshaling; D, Nanpaihe; E, Yugangkou. PFC is the percentage of positive fluorescence cells of the total cells. 5-AZA-CdR DTE: 5-AZA-CdR toxicity equivalent for demethylation potential ( $\mu$ M). All of the elements are the ICP-MS results for wet weight (mg/Kg). FSV is the standard value of the maximum levels for certain contaminants in marine fishes and crustaceans in China (GB 2762-2012). The FSV of Hg is replaced by those of methyl mercury. - The standard values of $\mathrm{Mn}$ and $\mathrm{Ni}$ are absent in this national food safety standard

The samples (MS06 and MS05) of Silurus asotus Linnaeus and Sinonovacula constricta from Beitangkou showed the worst DTE. According to the ICP-MS results for all eight samples, the abnormal rates of $\mathrm{Cd}$, As, and Cr were $87.5 \%, 37.5 \%$, and $12.5 \%$ with the maximum levels for certain food contaminants in China (GB 27622012), respectively.

\section{Discussion}

This study describes a method for the quantification of the total DNA demethylation potential of aquatic food samples within one week based on artificial methylation and the useful reporter gene. Currently, the Bohai Bay area is ranked as one of the most heavily polluted coastal areas in China $[17,18]$. It is therefore reasonable to explore the novel demethylation potential of the aquatic materials in this area for food safety and additional dietary health risk assessment.

One precondition of this study is the hypothesis that demethylation potential is possibly an innate part of the comprehensive negative effect of environmental pollution, with the counterpart of mutation and chromosome aberration [19]. Dozens of chemical pollutants revealed obvious effects on the steady methylation balance of genomic DNA. DNA methylation changes in whole blood are associated with exposure to environmental contaminants such as cadmium, mercury, lead, and bisphenol A [20], implying that the demethylation potential of the aquatic samples from heavily polluted marine areas should be a focus of health risk assessments of the local residents. Chronic exposure to arsenic leads to global DNA demethylation and aberrant gene expression [21-24], and even short-term exposure to arsenic can disturb DNA methylation patterns [25]. Environmental cadmium exposure is associated with DNA hypomethylation in peripheral blood [5, 26], and some aquatic samples extract with higher concentration of $\mathrm{Cd}$ also reveal obvious positive demethylation potential after the TDQ test.

The method of evaluating the demethylation potential of aquatic food samples is meaningful and few studies have reported on it thus far. A detection system for demethylating agents using an endogenous promoter CpG island was reported [10], but fluorescence cannot 
be quantified so precisely using only imaging and the results may overlook the confounding cytochromes P450 activation effect of environmental pollutants in hepatic cells. Moreover, cell lines using an endogenous, epigenetically silenced reporter are convenient for screening demethylating agents [27], but the methylation may be spontaneously lost after many generations and H1299 lung cancer cells are not the most suitable cell candidates due to the shortage of cytochromes P450 enzymes.

The TDQ method has several advantages in case of quantifying the total demethylation potential of food samples. First, the task of assessing the hazards of such complex mixtures is complicated, because the actual composition of these mixtures is rarely known and the behavior of mixture components is not fully understood [28]. To provide more information for food safety, the TDQ method can screen the samples with greater demethylation potential and likely samples may be selected for further scanning analysis of concrete pollutants. Second, the method can give an accurate relative quantification of the total demethylation potential of the aquatic sample extracts with 5-AZA-CdR DTE, which is more convenient for the direct comparison of health risks for different food samples. Third, comparing to cells from other organs, the Hep G2 cell line is more suitable for toxicity evaluation of pollutants and will help the TDQ test results more reliable. Not only are the hepatic cells just the target cells for toxicity test, but also the hepatic cells may help active pollutants possibly with cytochromes P450 enzymes as well [29, 30]. Moreover, the TDQ method is quick and easy to conduct using common equipments.

Despite the advantages above, compared with the endogenous promoter, a main drawback of TDQ is the exogenous CMV promoter used in this method. There are possibly some pollutants may have demethylation potential and not be sensitive to the demethylation of exogenous promoter, therefore false negative results for the TDQ test might existed. Strong fluorescence may result first from total demethylation potential and the possible later activation of transcription factors, meaning that false positive cases may appear in the results. The possibility of false positives is small, however, due to the rarity of samples with positive demethylation potential and strong activation of transcription factors. Therefore, the explaining the negative results of aquatic samples extract for TDQ test should be cautious. The TDQ test provides a primary evaluation of total demethylation potential, but the possible mechanisms underlying positive samples should be clarified with further research.

\section{Conclusions}

In summary, the TDQ is a meaningful and rapid assay for the relative quantification of the DNA demethylation potential of aquatic food extracts and is a candidate method for the total toxicity evaluation system for the health risk assessment of dietary environmental exposure with respect to epigenetic mechanisms.

\section{Methods \\ TDQ principle}

The paper presents a transient test for the demethylation potential of environmental samples. Hep G2 Cells are transfected transiently with a plasmid encoding fluorescent protein and with a highly methylated promoter. Demethylation can then be evaluated directly from an increase in fluorescence using flow cytometry.

The principle of the TDQ is as follows. First, the CMV promoters of the enhanced green fluorescence gene in pEGFP-C3 plasmid were heavily methylated artificially in vitro and the plasmids were transfected into Hep G2 cell lines using the FuGENE HD transfection reagent. Then, the extracts from different target seafood samples were incorporated into the common Hep G2 cell culture medium for simultaneous co-incubation. If the extract of aquatic sample A has strong total demethylation potential for the promoter, the methylation level will decrease and more GFP protein will be expressed, which will be shown by the observation of a strong green fluorescence of the experimental Hep G2 cells under microscopy. If the extract of aquatic sample B has weak demethylation potential, the methylation level will be almost unchanged and very little green fluorescence protein will be expressed, resulting in the observation of a light green fluorescence. Simultaneously using a standard curve of the positive demethylation agent 5AZA-CdR from the experiment, the total demethylation potential, termed the 5-AZA-CdR demethylation toxic equivalency (DTE), of all the extracts from the target aquatic samples can be quantified within one week (Fig. 1).

The total time for the TDQ test, not including the time for some other preparation work, is less than $70 \mathrm{~h}$. For The TDQ test of aquatic samples extract, there are some preparation should be completed before the initiation step of plasmid transfection. The pEGFP-C3 plasmid should be methylated in advance or stored in $-80^{\circ} \mathrm{C}$. The Hep G2 cells should be cultured in good performance for the later transient transfection. Once the TDQ test initiates, the whole experiment can't be paused until the terminal of the cells harvest. At the initiate Hour 0 , the cells should keep in good living performance; $24 \mathrm{~h}$ later, the cells are transfected with methylated pEGFP-C3 plasmid. At Hour 30, the cells are co-incubated with the 5-AZA$\mathrm{CdR}$ or samples extract for demethylating test. At Hour 60 , all the cells from different cell groups are harvested for fluorescence intensity test with flow cytometry at the same check time. 
Due to possible high concentration of pollutants in some aquatic samples extract and their possible toxicity to the Hep G2 cells, it is necessary to find a proper volume range of each extract for TDQ test. Before the initiation of TDQ test for aquatic samples, cellular toxicity of all samples extract should be assessed with MTS cellular viability assay in advance and a proper volume range of each extract added into the cell culture medium for TDQ test may be decided.

\section{Artificial methylation of pEGFP-C3 plasmid}

A large quantity of the commercial C3 plasmid was prepared with transformation of $\mathrm{E}$. coli in advance. Then the methylated pEGFP-C3 plasmid with enough volume (more than $500 \mathrm{mg}$ ) should be prepared and stored in $-80{ }^{\circ} \mathrm{C}$ after purification for later TDQ experiment. The total amount of methylated pEGFP-C3 plasmid for TDQ test of 10 aquatic samples extract should be no less than $1 \mathrm{mg}$. The volume of plasmid for a single methylation reaction system one time is about $500 \mathrm{ng}$ according to the instruction. The unmethylated plasmid DNA was digested with the restriction enzymes MspI and HpaII, and then the short DNA fragments containing the CMV promoter (S) and the complementary long DNA fragments (L) were recovered. Fragment S was methylated completely with M.SssI methyltransferase (New England Biolabs, MA, USA) according to the instructions. The methylated fragment $\mathrm{S}$ was then connected back to the unmethylated fragment $\mathrm{L}$ for a complete PEGFP-C3 Plasmid DNA cycle with T4 DNA ligase (New England Biolabs, MA, USA) by incubating overnight at $16{ }^{\circ} \mathrm{C}$. The methylated DNA cycle was purified with Plasmid DNA Purification System (Promega, WI, USA).

\section{Cell culture and MTS cellular viability assay}

According to the timeline of the TDQ test, Hour 0 is the initial time for test of aquatic samples. If you are planning to conduct the TDQ test for some samples, the cells should be cultured in good performance for the later transient transfection at Hour 0 . The human liver cancer cell line Hep G2 from the China Type Culture Collection (Chinese Academy of Medical Sciences, Beijing, China) grows in DMEM supplemented with $1 \%$ NEAA (Chinese Academy of Medical Sciences, Beijing, China) and $10 \%$ fetal bovine serum (JRH Bioscience, TX, USA) in $37^{\circ} \mathrm{C}$. Once the cells reached $90 \%$ confluence, cellular viability was measured using the -(4,5-dimethylthiazol-2-yl)-5-(3carboxymethoxyphenyl)-2-(4-sulfophenyl)-2H-tetrazolium (MTS) Cell Viability Assay (Promega Corporation, WI, USA) according to the manufacturer's instructions.

\section{Transfection of methylated pEGFP-C3 plasmid}

The good living performance of Hep G2 cells should be kept for at least $24 \mathrm{~h}$. Then the pEGFP-C3 plasmid with the fully methylated CMV promoter was transfected into the Hep G2 cells with the FuGENE HD transfection reagent (F. Hoffmann-La Roche Ltd, Basel, Switzerland) at Hour 24. Cells were seeded for a normal incubation condition at a density of $3 \times 10^{5}$ cells $/ 10$-cm dish. Approximately $2 \mu \mathrm{g}$ methylated pEGFP-C3 plasmid DNA was mixed with $100 \mathrm{ml}$ opti-MEM medium according to the instruction manual. This reagent was carefully pipetted into the medium containing the diluted pEGFP-C3 DNA $(0.02 \mu \mathrm{g} / \mu \mathrm{l})$. The transfection reagent and plasmid complex was incubated for $15 \mathrm{~min}$ at room temperature in advance, after which the complex was added to the cells in a drop-wise manner. The wells were swirled carefully to ensure distribution over the entire plate surface.

To keep efficiency and economy for the pEGFP-C3 plasmid transfection into the Hep G2 cells, it is meaningful to find the right and suitable volume of transfection reagent usage for common plasmid and cells density. After screening for the suitable volume (3, 4, 5,6 , or $7 \mu \mathrm{l}$ ) of the transfection reagent from a preexperiment of unmethylated plasmids, it was found that Hep G2 cells grew best and their fluorescence was brightest using $7 \mu \mathrm{l}$ of the transfection reagent. The percentages of positive fluorescence cells for transfection using $7 \mu \mathrm{l}$ of the transfection reagent are found between 31-52\%, which implies the transformation efficiency is acceptable.

\section{Cell treatment with 5-AZA-CdR and the aquatic sample extracts}

At Hour 30, the cells were treated with different concentrations of 5-AZA-CdR (Sigma, MO, USA), a positive demethylation agent for myelodysplastic syndrome therapy [31], and the target extract of the aquatic samples which was freshly dissolved in PBS and filtered through a $0.2-\mu \mathrm{m}$ membrane. At Hour 60, cells were harvested for different purposes, such as DNA methylation quantification of the CMV promoter, real-time polymerase chain reaction (PCR) of EGFP gene expression, fluorescent imaging, and the fluorescence intensity test with simultaneous flow cytometry.

\section{Methylation quantification of the CMV promoter}

The promoter methylation of the $\mathrm{C} 3$ plasmid inside the Hep G2 cells was quantified using bisulfite sequencing PCR (BSP), as reported previously [32]. There are 72 $\mathrm{CpG}$ sites located in the promoter region and the first part of the EGFP gene code region between 1 and $1046 \mathrm{bp}$. The total methylation level of $25 \mathrm{CpG}$ sites between 447 and 747 bp were investigated by bisulfite sequencing. In brief, all DNA, including the C3 plasmid within the cells, was collected by serial extraction with phenol/chloroform and ethanol precipitation as usual and was treated with bisulfite sodium. The PCR 
amplification product of the target CMV promoter region with methylation-specific primers was purified and linked with the pGEM-T vector (Promega, WI, USA) for transfection into the competent bacteria $E$. coli strain $\mathrm{DH} 5 \alpha$, and later blue-white screening. All of the positive clones were screened for further sequencing with universal primer T7 and SP6 at the Beijing Genomics Institute. The self-designed primers for BSP in the promoter were as follows: forward primer (23 nt) at the site of 447-469 bp with the sequence 5'TAATGGGAGTTT GTTTTGGTATT3', and reverse primer (25 nt) at the site of 1022-1046 bp with the sequence 5'TTATACTCCAA CTTATACCCCAAAA3'.

Relative quantification of EGFP mRNA with real-time PCR The method of relative quantification of EGFP mRNA via real-time PCR is as previously reported [33]. In brief, total RNA was isolated from cells with Trizol reagent (Invitrogen, AL, USA). First strand cDNA was synthesized using the PrimeScriptTM RT Reagent Kit (Takara, Dalian, China) from an equal amount of RNA. Quantitative PCR was performed with stratagene MX3100 QPCR (Bio-Rad Laboratories, CA, USA) using SYBR Premix Ex TaqTM (Takara, Dalian, China). Samples were analyzed in triplicate. Gene expression values were calculated based on the comparative quantitative method and normalized to values obtained from the amplification of the endogenous control glyceraldehyde-3-phosphate dehydrogenase (GAPDH). The $\triangle \mathrm{Ct}$ values for all genes were determined relative to GAPDH. The $\Delta \Delta \mathrm{Ct}$ values were calculated using the treated group means relative to the control group means. The fold change data were calculated from the $\Delta \Delta \mathrm{Ct}$ values. Quantitative PCR amplification was carried out with the following sets of primers. Primers sequence for the EGFP gene: 5'TAATGGGAGTTTGTTTTGGTATT-3' (sense), 5'-TTA TACTCCAACTTATACCCCAAA A-3' (antisense); primers sequence for the GAPDH gene: 3'-AGGT GAAGGTCGGAGTCAACG-3' (sense), 5' -AGGGGT CATTGATGGCAACA-3' (antisense). For both genes, PCR was performed for 40 cycles at an annealing temperature of $60{ }^{\circ} \mathrm{C}$.

\section{Fluorescence intensity detection of cells by flow cytometry}

Fluorescence intensity was measured first with imaging and then more accurately with flow cytometry. First, cells were washed with PBS and fixed with $4 \%$ paraformaldehyde. Fluorescence was observed using an Olympus IX71 microscope (Olympus, Tokyo, Japan), and images were analyzed with Image Pro Plus 6.0 software for Windows (Media Cybernetics, USA). Cell fluorescence was then assayed using flow cytometry (Altra, Beckman Coulter, USA). One ml of PBS puff was added uniformly to the 24-well plates for cell detachment, after which the cells was transferred into a $1.5-\mathrm{ml}$ tube to remove the supernatant after centrifugation at $2000 \mathrm{~g}$ for $3 \mathrm{~min}$. All of the cells in the stream-specific tube were pumped into the flow cytometry to detect the percentage of cells with positive EGFP fluorescence.

\section{Sampling sites around Bohai Bay and aquatic sampling}

The environmental monitoring report shows that Haihe River has been awarded the worst possible water quality rating for 20 years. The aquatic sampling sites were located around the estuary of the Haihe River in the Bohai Bay area. Approximately $20 \mathrm{~km}$ separated each of the five sampling sites (Additional file 4: Figure S1), and sampling was carried out from September to October of 2011. The collected mollusks were depurated in filtered seawater for approximately $24 \mathrm{~h}$ before being transported to the laboratory with ice freezing. The mollusks' edible soft tissues were excised by stainless steel scalpels and then thoroughly rinsed with MQ water to remove extraneous impurities. After sufficient homogenization by a blender, the samples were kept at $-20{ }^{\circ} \mathrm{C}$ until analysis. Different species of mollusks were identified according to the catalog of marine mollusks in reference books.

\section{Pretreatment of aquatic samples for TDQ test and ICP-MS analysis}

Approximately $50 \mathrm{~g}$ (wet weight) of aquatic soft tissues were divided into five parts and each part was weighed in a PTFE digestion container. Fifty $\mathrm{ml}$ of concentrated nitric acid was added to each part and left to predigest overnight at $40{ }^{\circ} \mathrm{C}$. Twenty $\mathrm{ml}$ of $30 \%$ hydrogen peroxide was then added after cooling. Thereafter the container was covered and placed in a high-pressure stainless steel bomb in an oven. The oven temperature was increased to $160{ }^{\circ} \mathrm{C}$ and maintained for $4 \mathrm{~h}$. After cooling, the total solution of five parts was collected to dry and then diluted with $5 \mathrm{ml}$ Milli-Q water $(5 \mathrm{~g} / \mathrm{ml}, 10 \times)$.

Four $\mathrm{ml}$ of aquatic extraction solution was centrifuged with $5000 \mathrm{~g}$ for $10 \mathrm{~min}$ and the aqueous supernatant was kept sterile after filtration for the next TDQ test using $0.22 \mu \mathrm{m}$ microfiltration membranes. The other $1 \mathrm{ml}$ solution was transferred to a PET bottle and stored at $-20{ }^{\circ} \mathrm{C}$ for later analysis with ICP-MS $(\mathrm{Cd}, \mathrm{As}, \mathrm{Cr}$, $\mathrm{Mn}, \mathrm{Ni}, \mathrm{Pb}$, and $\mathrm{Hg}$ ). All elements were consistent with the certified values, with the recoveries ranging from $81.62 \%$ to $118.70 \%$. The detection limits of $\mathrm{Cd}, \mathrm{As}, \mathrm{Cr}$, $\mathrm{Mn}, \mathrm{Ni}, \mathrm{Pb}$ and $\mathrm{Hg}$ were 5.0, 5.0, 30, 60.00, 5.0, 10.0, and $5.0 \mu \mathrm{g} / \mathrm{Kg}$, respectively.

\section{Demethylation potential quantification of aquatic samples with the TDQ test}

For aquatic samples extract, if the concentrations of some pollutants contained are very high, the extract 
might be toxic to the Hep G2 cells. Therefore, it is necessary for us to find a proper volume range of each extract for TDQ test. With an MTS assay for each sample in advance, the proper volume range of each target sample may be found for TDQ test usually. Using the same method as 5-AZA-CdR, the extraction solution of each aquatic sample was added to the different wells at a concentration of $1 \times$ in 24-well plate at Hour 30. There were three parallels for each sample. The fluorescence intensity of each well was measured first with imaging and then with flow cytometry analysis at Hour 60 .

\section{Statistical analysis}

The total demethylation potential of an aquatic sample is expressed by the DTE of 5-AZA-CdR after the TDQ test. All statistical analysis was performed using SPSS16.0 for Windows. Linear regressions and Pearson correlation was conducted to evaluate the association between the concentrations of 5-AZA-CdR and the methylation levels of the CMV promoter, the relative levels of EGFP mRNA and fluorescence intensity. Data were expressed as the mean \pm SD. Differences with a P value of less than 0.05 were considered to be statistically significant, ANOVA was for difference analysis of groups.

\section{Additional files}

Additional file 1: Table S1. Quantitative real-time PCR of the EGFP mRNA for 5-AZA-CdR treated Hep G2 cell lines. (PDF $114 \mathrm{~kb}$ )

Additional file 2: Table S2. The detection limit of TDQ experiment with repetitive tests of 5-AZA-CdR. (PDF $11 \mathrm{~kb}$ )

Additional file 3: Table S3. The optimal check time for TDQ test with repetitive tests of 5-AZA-CdR treatment. (PDF $11 \mathrm{~kb}$ )

Additional file 4: Figure S1. Aquatic sampling sites around the Haihe river estuary of Bohai Sea. All five sites are $15 \mathrm{~km}$ from the coastal line and $20 \mathrm{~km}$ apart. (PDF $755 \mathrm{~kb}$ )

\section{Abbreviations \\ 5-AZA-CdR: 5-Aza-2'-deoxycytidine; TDQ: quantification method of total demethylation potential; DTE: demethylation toxic equivalency; \\ PFC: percentage of positive fluorescence cells.}

\section{Competing interests}

The authors declare that they have no competing interests.

\section{Authors' contributions}

$X W$ conceived the project and designed the experiments along with JZ, MH and $Y Y . Y Q, X W, C G, L B, J W$ and $Y J$ performed the laboratory work. $Y W$ and $J N$ analyzed the results. $Z L$ and $Y Y$ collected and analyzed the aquatic samples. XW and YQ wrote the manuscript. All authors read and approved the final manuscript.

\section{Acknowledgements}

This study was partially supported by the National Natural Science Foundation of China (20907047), the National Basic Research Program of China (2012CB525005), the National Environmental Protection Public Welfare Science and Technology Research Program of China (201309045), and the National Non-profit Institute Research Grant of CRAES (2008KYYW05). The authors wish to thank Dr. Mats Tysklind for helpful suggestions and pertinent advice on the manuscript. Thank the reviewers for extensive comments.

\section{Author details}

'State Key Laboratory of Environmental Criteria and Risk Assessment, Chinese Research Academy of Environmental Sciences, Beijing 100012, China.

${ }^{2}$ College of Life Science and Bioengineering, Beijing University of

Technology, Beijing 100124, China. ${ }^{3}$ School of Public Health, Anhui Medical University, Hefei 230032, China. ${ }^{4}$ Institute of Environmental Health and Related Product Safety, Chinese Center for Disease Control and Prevention, Beijing 100021, China.

Received: 6 November 2014 Accepted: 13 November 2015

Published online: 26 November 2015

\section{References}

1. Collins AR. The comet assay for DNA damage and repair: principles, applications, and limitations. Mol Biotechnol. 2004;26:249-61.

2. Miceli M, Bontempo P, Nebbioso A, Altucci L. Natural compounds in epigenetics: a current view. Food Chem Toxicol. 2014;73C:71-83.

3. Hervouet E, Hulin P, Vallette FM, Cartron PF. Proximity ligation in situ assay for monitoring the global DNA methylation in cells. BMC Biotechnol. 2011;11:31.

4. Zhang J, Fu Y, Li J, Wang J, He B, Xu S. Effects of subchronic cadmium poisoning on DNA methylation in hens. Environ Toxicol Pharmacol. 2009;27:345-9.

5. Hossain MB, Vahter M, Concha G, Broberg K. Low-level environmental cadmium exposure is associated with DNA hypomethylation in Argentinean women. Environ Health Perspect. 2012;120:879-84.

6. Teneng I, Montoya-Durango DE, Quertermous JL, Lacy ME, Ramos KS. Reactivation of $\mathrm{L} 1$ retrotransposon by benzo(a)pyrene involves complex genetic and epigenetic regulation. Epigenetics. 2011;6:355-67.

7. Bulletin of China's Environmental Status for the Year of 2013 [http://www. soa.gov.cn/zwgk/hygb/zghyhjzlgb/201403/t20140324_31065.html] Accessed 24 November 2015.

8. Wang YW, Liang L, Shi JB, Jiang GB. Study on the contamination of heavy metals and their correlations in mollusks collected from coastal sites along the Chinese Bohai Sea. Environ Int. 2005;31:1103-13.

9. Zhang W, Wang WX. Large-scale spatial and interspecies differences in trace elements and stable isotopes in marine wild fish from Chinese waters. J Hazard Mater. 2012;215:65-74.

10. Okochi-Takada E, Ichimura S, Kaneda A, Sugimura T, Ushijima T. Establishment of a detection system for demethylating agents using an endogenous promoter CpG island. Mutat Res. 2004:568:187-94.

11. Lin YS, Shaw AY, Wang SG, Hsu CC, Teng IW, Tseng MJ, et al. Identification of novel DNA methylation inhibitors via a two-component reporter gene system. J Biomed Sci. 2011;18:3

12. Watson RE, Goodman Jl. Epigenetics and DNA methylation come of age in toxicology. Toxicol Sci. 2002;67:11-6.

13. Szyf M. The implications of DNA methylation for toxicology: toward toxicomethylomics, the toxicology of DNA methylation. Toxicol Sci. 2011;120:235-55.

14. Watson RE, McKim JM, Cockerell GL, Goodman Jl. The value of DNA methylation analysis in basic, initial toxicity assessments. Toxicol Sci. 2004;79:178-88.

15. Goodman Jl, Augustine KA, Cunnningham ML, Dixon D, Dragan YP, Falls JG, et al. What Do We need to know prior to thinking about incorporating an epigenetic evaluation into safety assessments?(2). Toxicol Sci. 2010;116:375-81.

16. Booth MJ, Branco MR, Ficz G, Oxley D, Krueger F, Reik W, et al. Quantitative sequencing of 5-methylcytosine and 5-hydroxymethylcytosine at singlebase resolution. Science. 2012;336:934-7.

17. Pan K, Wang WX. Trace metal contamination in estuarine and coastal environments in China. Sci Total Environ. 2012;421:3-16.

18. Gao XL, Zhou FX, Chen CTA. Pollution status of the Bohai Sea: An overview of the environmental quality assessment related trace metals. Environ Int. 2014;62:12-30

19. Wade PA, Archer TK. Epigenetics: environmental instructions for the genome. Environ Health Perspect. 2006;114:A140-141.

20. Hanna CW, Bloom MS, Robinson WP, Kim D, Parsons PJ, vom Saal FS, et al. DNA methylation changes in whole blood is associated with exposure to the environmental contaminants, mercury, lead, cadmium and bisphenol A, in women undergoing ovarian stimulation for IVF. Hum Reprod. 2012;27:1401-10. 
21. Chen H, Li S, Liu J, Diwan BA, Barrett JC, Waalkes MP. Chronic inorganic arsenic exposure induces hepatic global and individual gene hypomethylation: implications for arsenic hepatocarcinogenesis. Carcinogenesis. 2004;25:1779-86.

22. Liu J, Benbrahim-Tallaa L, Qian X, Yu L, Xie Y, Boos J, et al. Further studies on aberrant gene expression associated with arsenic-induced malignant transformation in rat liver TRL1215 cells. Toxicol Appl Pharmacol. 2006;216:407-15.

23. Reichard JF, Schnekenburger M, Puga A. Long term low-dose arsenic exposure induces loss of DNA methylation. Biochem Biophys Res Commun. 2007:352:188-92.

24. Xie Y, Trouba KJ, Liu J, Waalkes MP, Germolec DR. Biokinetics and subchronic toxic effects of oral arsenite, arsenate, monomethylarsonic acid, and dimethylarsinic acid in v-Ha-ras transgenic (Tg.AC) mice. Environ Health Perspect. 2004;112:1255-63.

25. Sciandrello G, Caradonna F, Mauro M, Barbata G. Arsenic-induced DNA hypomethylation affects chromosomal instability in mammalian cells. Carcinogenesis. 2004;25:413-7.

26. Doi T, Puri P, McCann A, Bannigan J, Thompson J. Epigenetic effect of cadmium on global de novo DNA hypomethylation in the cadmiuminduced ventral body wall defect (VBWD) in the chick model. Toxicol Sci. 2011;120:475-80.

27. Cell line for screening demethylating agents using an endogenous epigenetically silenced reporter [http://gtp.autm.net/technology/view/ 27027] Accessed 24 November 2015

28. White PA. The genotoxicity of priority polycyclic aromatic hydrocarbons in complex mixtures. Mutat Res. 2002;515:85-98.

29. Chiang TS, Yang KC, Chiou LL, Huang GT, Lee HS. Enhancement of CYP3A4 activity in Hep G2 cells by lentiviral transfection of hepatocyte nuclear factor-1 alpha. PLoS One. 2014;9:e94885.

30. Balusikova K, Kovar J. Alcohol dehydrogenase and cytochrome P450 2E1 can be induced by long-term exposure to ethanol in cultured liver HEP-G2 cells. In Vitro Cell Dev Biol Anim. 2013:49:619-25.

31. Arzuaga X, Calcano W, Elskus A. The DNA de-methylating agent 5-azacytidine does not restore CYP1A induction in PCB resistant Newark Bay killifish (Fundulus heteroclitus). Marine environmental research. 2004;58:517-20.

32. Wang $X$, Zhang $C$, Zhang L, Xu S. High-throughput assay of DNA methylation based on methylation-specific primer and SAGE. Biochem Biophys Res Commun. 2006;341:749-54.

33. Lou J, Wang Y, Yao C, Jin L, Wang X, Xiao Y, et al. Role of DNA methylation in cell cycle arrest induced by $\mathrm{Cr}(\mathrm{VI})$ in two cell lines. PLoS One. 2013;8:e71031.

\section{Submit your next manuscript to BioMed Central and we will help you at every step:}

- We accept pre-submission inquiries

- Our selector tool helps you to find the most relevant journal

- We provide round the clock customer support

- Convenient online submission

- Thorough peer review

- Inclusion in PubMed and all major indexing services

- Maximum visibility for your research 